\title{
Applicability of the universal thermal climate index for predicting the outbreaks of respiratory tract infections: a mathematical modeling approach
}

\author{
Jerzy Romaszko ${ }^{1}$ (D) Rafał Skutecki ${ }^{1}$ - Maciej Bocheński ${ }^{2}$. Iwona Cymes ${ }^{3} \cdot$ Ewa Dragańska $^{3} \cdot$ Piotr Jastrzębski $^{2}$. \\ Irena Morocka-Tralle ${ }^{2} \cdot$ Rakesh Jalali $^{4} \cdot$ Anna Jeznach-Steinhagen $^{5} \cdot$ Katarzyna Glińska-Lewczuk $^{3}$
}

Received: 2 January 2019 /Revised: 29 April 2019 / Accepted: 30 May 2019 /Published online: 22 July 2019

(C) The Author(s) 2019

\begin{abstract}
Respiratory tract infections (RTI) are one of the most frequent reasons for medical consultations. As air temperature decreases, but also in connection with other meteorological parameters, evident seasonal fluctuations in the number of consultations for RTI can be observed. The Universal Thermal Climate Index (UTCI) is a complex meteorological index derived from an analysis of human thermal balance that depends on air temperature, air humidity, and wind speed. Our aims were to check if this index, although never used before for that purpose, is an adequate tool for forecasting seasonal increases in RTI prevalence. This study is a retrospective analysis of patients' consultations with general practitioners in the period of 2012-2015 (453,674 records) recorded in the city of Olsztyn (Poland), which is characterized by a cold climate type $(\mathrm{Dfb})$. The values of air temperature, atmospheric pressure, relative air humidity, wind speed, and UTCI were used for a statistical analysis and a mathematical analysis of curve fitting in order to determine correlations between analyzed meteorological parameters and a number of medical consultations for RTI. Analysis of the number of medical consultations for RTI revealed an evident seasonal pattern in a 4-year observation period, with a strong inverse correlation between the number of patients with RTI and the UTCI. A statistically significant increase in the number of patients with RTI appeared when the UTCI decreased, especially when it reached the classes of strong cold stress and very strong cold stress. In conclusion, the UTCI is a valuable predictive parameter for forecasting seasonal increases in RTI cases. Its decrease may initiate a seasonal increased prevalence. This effect is strongest about the 10th day following a change in the thermal climate conditions and is not continuous. A larger number of consultations for RTI after weekends and holidays (the Monday effect) may blur the results of statistical analyses.
\end{abstract}

Jerzy Romaszko

jerzy.romaszko@uwm.edu.pl

1 School of Medicine, Family Medicine Unit, University of Warmia and Mazury in Olsztyn, Warszawska 30, 10-082 Olsztyn, Poland

2 Faculty of Mathematics and Computer Science, University of Warmia and Mazury in Olsztyn, Olsztyn, Poland

3 Department of Water Resources, Climatology and Environmental Management, University of Warmia and Mazury in Olsztyn, Olsztyn, Poland

4 School of Medicine, Department of Emergency Medicine, University of Warmia and Mazury in Olsztyn, Olsztyn, Poland

5 Clinical Dietetics Department, Medical University of Warsaw, Warszawa, Poland

\section{Introduction}

Respiratory tract infections (RTI) are one of the most frequent reasons for medical consultations within a healthcare system. It is estimated that a quarter of the population visits general practitioners (GP) for RTI each year (NICE CfCPa 2008). These infections, irrespective of their etiology (viral, bacterial), are characterized by a similar, usually a few days long, incubation period, a similar transmission mode by droplets, and - especially in a moderate climate - a commonly known relationship between a drop in air temperature, an increase in air humidity, and an increase in the number of RTI cases is observed (du Prel et al. 2009). Nastos and Matzarakis in their study based in Athens (Greece, Csa, temperate climate type, with dry and hot summer according to the updated Köppen- 
Geiger climate classification) reported a statistically significant difference in the number of GP consultations depending on air temperature (minimum, maximum and mean) and absolute humidity (Peel et al. 2007). They also reported a 10-day lag between worsened weather and RTI epidemiological onset (Nastos and Matzarakis 2006). When analyzing data from Kajaani, Finland (Dfc, cold climate type, without dry season and with cold summer), characterized by a different climate zone, Makinen et al. obtained a statistically significant correlation between cases of RTI and decreased air temperature and/or decreased humidity and a similar 14-day lag for the occurrence of RTI (Makinen et al. 2009). Hajat et al., based on the dataset collected from primary care settings in 16 urban locations in the UK, also described a relationship between a drop in temperature and the number of consultations for RTI (Hajat et al. 2004). They reported that this effect proved stronger in the north and weaker in the south of the country. This relationship between RTI occurrences and temperature has been also described in several other studies (Danielides et al. 2002; Fielder 1989). In 2009, when analyzing reasons for the hospitalization of children due to viral causes in Mainz (Germany), Prel et al. reported an association between meteorological parameters and the cases of hospitalization for RTI. According to their data, rhinoviruses (the most common infectious agents) preferred a humid climate whereas many other respiratory pathogens, such as RSV (respiratory syncytial virus) and influenza A, favored low temperatures (du Prel et al. 2009).

The increased interest of researchers in biometeorological conditions for RTI occurrences includes not only outdoor air temperatures (maximum, minimum, mean), but also wind speed, air humidity, and other meteorological parameters (Liu et al. 2016). Biometeorology employs various methods and indices as well as mathematical models to determine relationships between meteorological parameters and human health (Epstein and Moran 2006; Lowe et al. 2018).

More complex bioclimatic indices represent relationships between values of a few basic meteorological parameters as empirical formulas. One of the first indices, introduced in the 1940s, was the wind chill index (WCI), which is especially useful when assessing winter conditions (Court 1948). Other indices include, for instance, effective temperature (ET), normal effective temperature (NET), heat stress index (HSI), or humidex (Li and Chan 2000; Masterton and Fa 1979; Osczevski and Bluestein 2005). It should be remembered, however, that most of these indices do not relate directly to physiological reactions of the human organism in response to changing thermal conditions. Consequently, a number of complex indices have been designed based on the analysis of human thermal balance, such as physiological equivalent temperature (PET), perceived temperature (PT), physiological subjective temperature (PST), and physiological strain $(\mathrm{PhS})$ (Blazejczyk 1994; Błażejczyk and McGregor 2008;
Laschewski and Jendritzky 2002; Matzarakis and Mayer 1996). The most recent index from this group is the universal thermal climate index (UTCI), which was developed as a result of international cooperation within the framework of the COST Action 730 (Cooperation in Science and Technical Development) in the years 2005-2009 (Brode et al. 2012; Jendritzky et al. 2009). The UTCI is based on the analysis of human thermal balance with the application of the Fiala model that is one of the most advanced multinode thermoregulatory models (Fiala et al. 2012; Fiala et al. 1999, 2001). The UTCI is a universal index due to its appropriateness for thermal assessments in all climates, seasons, and scales (Pantavou et al. 2018; Blazejczyk et al. 2012; McGregor 2012). As compared with other indices, the UTCI is more sensitive to changes in the following ambient stimuli: temperature, solar radiation, humidity, and wind speed (Blazejczyk et al. 2012). Additionally, the UTCI, unlike, e.g., PET, is independent of personal characteristics such as age, gender, specific activities, and clothing (Bröde 2000).

Although the relationship between seasonal increases in RTI occurrences and a drop in temperature is well documented, the time lag between these two phenomena still remains unclear. Moreover, it should be remembered that this correlation is not continuous and the worsening of weather conditions is only one of the elements that initiate an epidemiological cascade. Work organizational issues are one of the factors that blur methodological correctness of analyses concerning the number of patients admitted within the framework of the healthcare system. If the daily (or even hourly) analysis of meteorological parameters is methodologically sound, the analysis of patients' daily admissions raises doubts due to the organizational framework of the healthcare system (Buckingham-Jeffery et al. 2017; Whynes et al. 1999). The frequency of patients' daily visits as regards outpatient clinics is uneven and ranges from a minimal number on weekends to maximal values on Mondays, a phenomenon that we termed "the Monday effect".

In this paper, we suggest that the UTCI should be applied to predict consultations for RTI within the healthcare system framework just by monitoring daily UTCI values based on a mathematical model attenuating "the Monday effect".

\section{Materials and methods}

\section{Study population}

The study is a retrospective analysis of an epidemiological dataset based on the register of patients' admissions within the framework of the healthcare system in the city of Olsztyn (north-eastern Poland). Olsztyn has a population of 180,000 inhabitants. The dataset was created on the 
basis of medical records from two primary care institutions (non-public primary healthcare centre Atarax and Pantamed limited liability company), a service register of the Regional Ambulance Station and a register of admissions at the Emergency Department of the Regional Specialist Hospital in Olsztyn. Primary care centers are opened from 8:00 to 18:00 h Monday to Friday, and provide medical care for about 20,500 patients daily (the active list changes every day; however, these changes are minimal as compared to the total number of patients). The maximal and minimal records of admitted patients in both practices within the analyzed period were Atarax; 6402/6855, Pantamed; 13913/14147, respectively. The Emergency Department of the Regional Hospital is the largest one out of three departments in the city of Olsztyn. Patients are referred there by their GPs, are brought in by the Emergency Service, and report directly if they believe their health conditions require immediate help. The Regional Ambulance Station provides services for the municipal commune of Olsztyn and three smaller sub-municipal communes, including the population of approx. 200,000 people in total. Both the Emergency Department of the Regional Hospital and the Regional Ambulance Station work within the 24/7 service system. In our study, we used all medical records registered in these institutions from 01.01.2012 to 31.12.2015, consisting in total of 452,674 records. From this number, 67548 records were selected for the purpose of this analysis, as they represented diagnoses from J00 to J22 (respiratory tract infections) and A38 (scarlet fever) according to ICD 10 (the 10th revision of the International Statistical Classification of Diseases and Related Health Problems), (WHO 1992).

During the 4-year observation period, 67,548 patients with RTI were recorded, $56.8 \%$ of whom were females and $43.2 \%$ males (Table 1). Out of the total number of patients, as many as $33,401(49.5 \%)$ infected patients were younger than 16 years of age and 15,237 (22.6\%) patients were between the ages of $17-35$, while $5626(8.32 \%)$ were older than 65 years of age (Table 1$)$.

Depending on the age group, RTI amounted to $4-5 \%$ up to $50-51 \%$ of the causes for consultations within the healthcare system (Fig. 1).

The majority $(96.6 \%)$ of the examined consultations occurred in primary care centers (opened from Monday to Friday). Significant differences $(p<0.05)$ in the number of consultations were revealed for particular weekdays (Table 2).

\section{Meteorological data}

Meteorological data for the period of analysis, i.e., 20122015, were obtained from the Olsztyn weather station belonging to the Institute of Meteorology and Water Management in Warsaw, Poland. Olsztyn is characterized by a cold climate, without dry season and with warm summer (Dfb, Peel et al. 2007). An evident annual seasonal pattern of weather conditions determines the occurrence of 4 seasons. January was the coldest month during the analyzed period, with a mean air temperature of $-2.5^{\circ} \mathrm{C}$; July was the warmest, with a mean temperature of $18.9{ }^{\circ} \mathrm{C}$. The annual precipitation rate was $550 \mathrm{~mm}$, and relative humidity amounted to $79 \%$. The mean wind speed was $3 \mathrm{~m} / \mathrm{s}$, whereas the strongest wind was recorded in winter (December, January).

On each day, UTCI values were calculated for 6:00, 12:00, and 18:00 Coordinated Universal Time (UTC). For the calculations of universal thermal climate index, the following simplified equation (Eq. 1) was applied (Błażejczyk 2011):

$$
\mathrm{UTCI}_{\mathrm{h}}=3.21+0.872 \cdot \mathrm{T}_{\text {air }}+0.2459
$$

$$
\cdot \text { Mrt-2.5078 } \cdot \text { WS-0.0176 } \cdot \text { RH }
$$

where $\mathrm{UTCI}_{\mathrm{h}}$ universal thermal climate index calculated for hours (h); 6:00, 12:00, and 18:00 using meteorological data from these hours, $T_{\text {air }}$ air temperature $\left({ }^{\circ} \mathrm{C}\right)$, Mrt mean

\begin{tabular}{|c|c|c|c|c|c|c|c|c|c|c|}
\hline \multirow[t]{2}{*}{ Age group } & \multicolumn{4}{|l|}{ Females } & \multicolumn{4}{|l|}{ Males } & \multicolumn{2}{|c|}{ Total males and females } \\
\hline & Symbol & Number & $\mathrm{F}(\%)$ & Total $(\%)$ & Symbol & Number & $\mathrm{M}(\%)$ & Total $(\%)$ & Number & Total $(\%)$ \\
\hline 0 to 1 & $\mathrm{~F} 1$ & 2355 & 6.14 & 3.49 & M1 & 2926 & 10.03 & 4.33 & 5281 & 7.82 \\
\hline 2 to 3 & $\mathrm{~F} 2$ & 3944 & 10.28 & 5.84 & M2 & 4235 & 14.51 & 6.27 & 8179 & 12.12 \\
\hline 4 to 6 & $\mathrm{~F} 3$ & 4985 & 12.99 & 7.38 & M3 & 5289 & 18.12 & 7.83 & 10,274 & 15.21 \\
\hline 7 to 16 & F4 & 4940 & 12.88 & 7.31 & M4 & 4727 & 16.20 & 7.00 & 9667 & 14.31 \\
\hline 17 to 35 & F5 & 9633 & 25.11 & 14.26 & M5 & 5604 & 19.20 & 8.30 & 15,237 & 22.56 \\
\hline 36 to 64 & F6 & 8732 & 22.76 & 12.93 & M6 & 4552 & 15.60 & 6.74 & 13,284 & 19.66 \\
\hline$\geq 65$ & F7 & 3772 & 9.83 & 5.58 & M7 & 1854 & 6.35 & 2.74 & 5626 & 8.32 \\
\hline Total & - & 38,361 & 100 & 56.79 & - & 29,187 & 100 & 43.21 & 67,548 & 100 \\
\hline
\end{tabular}

Table 1 Age groups of patients with RTI in Olsztyn in the period of 2012-2015 
Fig. 1 Share of age groups and gender in admissions due to infectious diseases versus total number of admissions (gray). F stands for females, while $\mathrm{M}$ stands for males. F1 and M1 from 0 to 1 year old; $F 2$ and $\mathrm{M} 2$ from 2 to 3 years old; F3 and M3 from 4 to 6 years old; $\mathrm{F} 4$ and M4 from 7 to 16 years old; F5 and M5 from 17 to 35 years old; F6 and M6 from 36 to 64 years old; F7, M7 $\geq$ 65 years old.

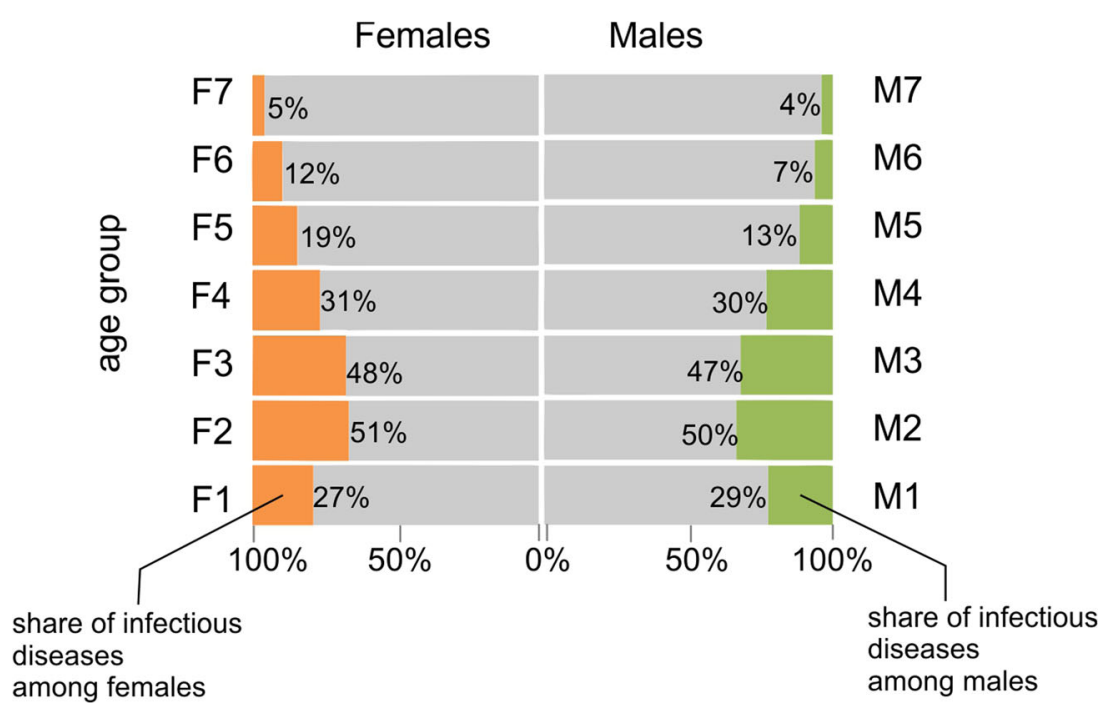

radiant temperature $\left({ }^{\circ} \mathrm{C}\right)$, WS wind speed at $10 \mathrm{~m}$ above ground $\left(\mathrm{m} \mathrm{s}^{-1}\right)$, RH relative humidity of air $(\%)$.

From the UTCI values calculated on a given day, the value indicating the most severe conditions was selected to represent and assess thermal load on that day. UTCI values are classified by taking into account the intensity of the organism's physiological reactions during specific meteorological conditions, which is associated with the necessity of employing various protective means against overheating and hypothermia. Heat stress may appear on days characterized by high temperature and intensive solar radiation. Among the UTCI heat stress classes that appeared during the period of our study were UTCI_+1 (moderate) (with temperatures from 26.1 to $32.0{ }^{\circ} \mathrm{C}$ ), UTCI_+2 (strong) (from 32.1 to $38.0{ }^{\circ} \mathrm{C}$ ), UTCI_+3 (very strong) $\left(38.1\right.$ to $\left.46.0{ }^{\circ} \mathrm{C}\right)$, and UTCI_+4 (extreme) $\left(>46.0^{\circ} \mathrm{C}\right)$. Cold stress, on the other hand, might be experienced when air temperature is low and wind speed is high. Among UTCI cold stress classes were indicated: UTCI

Table 2 Number of admissions (\%) of patients with RTI in Olsztyn in the period of 2012-2015 on specific weekdays

\begin{tabular}{ll}
\hline Day of week & Admissions (\%) \\
\hline Monday & $27.53^{\mathrm{d}}$ \\
Tuesday & $19.04^{\mathrm{c}}$ \\
Wednesday & $17.25^{\mathrm{bc}}$ \\
Thursday & $16.66^{\mathrm{b}}$ \\
Friday & $18.49^{\mathrm{bc}}$ \\
Saturday & $0.54^{\mathrm{a}}$ \\
Sunday & $0.49^{\mathrm{a}}$ \\
\hline
\end{tabular}

Statistical significance was determined with the variance analysis (one-way ANOVA, post hoc Tukey's HSD test). Groups of mean values that do not differ statistically are marked with the same letters (standard error: mean square (MS) between groups $=689.65$, degree of freedom $(\mathrm{df})=1454.0$, for $p<0.0001)$
-1 (slight) $\left(0.1\right.$ to $\left.9.0^{\circ} \mathrm{C}\right), \mathrm{UTCI}_{-}-2$ (moderate) (from 12.9 to $\left.2370.0^{\circ} \mathrm{C}\right)$, UTCI_-3 (strong) $(-26.9$ to -13.0$)$, UTCI_-4 (very strong) $\left(\right.$ from -39.9 to $-27.0{ }^{\circ} \mathrm{C}$ ), and UTCI -5 (extreme) $\left(<-40.0^{\circ} \mathrm{C}\right)$. Thermoneutral conditions (UTCI class $\mathrm{O}$ ) refer to conditions when UTCI values indicate the absence of heat stress, thus ranging from 9.1 to $26^{\circ} \mathrm{C}$. Based on such assumptions, it is possible to divide thermal conditions into classes and ascribe patients with RTI to these classes (Table 3).

\section{Statistical analyses}

A preliminary and exploratory statistical analysis was carried out by a traditional approach, i.e., by evaluating the relationships between daily consultations rates and daily weather data by using a regression analysis. This examination was performed for the overall group of 67,548 patients and for seven different age groups: younger than 1 year; from 2 to 3 years; from 4 to 6 years; from 7 to 16 years; from 17 to 35 years; from 36 to 64 years; and older than 65 years of age.

A one-way analysis of variance (ANOVA) with the Tukey's multiple comparison test $(p<0.05)$ as a post hoc procedure was used to test differences between numbers of admissions for RTI during consecutive days of a week (Table 2) as well as between groups of infected patients in UTCI classes. The mean abundances and standard deviations $( \pm \mathrm{SD})$ were calculated using Dell ${ }^{\mathrm{TM}}$ Statistica ${ }^{\mathrm{TM}} 13.1$.

Values of mean daily air temperature (Tair), air pressure $\left(\mathrm{P}_{\mathrm{atm}}\right)$, relative humidity $(\mathrm{RH})$, wind speed (WS), and UTCI were used to analyze the relationship between the occurrences of infectious diseases (RTI) and weather conditions via a partial least squares regression (PLS-R). This is a technique that combines features from a principal component analysis (PCA) and a multiple linear regression method (Fleming et al. 2002). The PLS-R model is based on a linear combination of the 
Table 3 Percentage share of admissions for RTI depending on the UTCI class and month for Olsztyn in the period of 2012-2015

\begin{tabular}{|c|c|c|c|c|c|c|c|c|c|c|c|}
\hline \multirow[t]{3}{*}{ UTCI } & \multicolumn{5}{|c|}{ Cold stress } & \multirow{2}{*}{$\begin{array}{l}\text { Thermo- } \\
\text { neutral } \\
\text { conditions }\end{array}$} & \multicolumn{4}{|l|}{ Heat stress } & \multirow{3}{*}{$\begin{array}{l}\text { Total } \\
(\%)\end{array}$} \\
\hline & Extreme & Very strong & Strong & Moderate & Slight & & Moderate & Strong & $\begin{array}{l}\text { Very } \\
\text { strong }\end{array}$ & Extreme & \\
\hline & $<-40.0$ & $\begin{array}{l}-39.9 \text { to } \\
-27.0\end{array}$ & $\begin{array}{l}-26.9 \text { to } \\
-13.0\end{array}$ & $\begin{array}{l}-12.9 \text { to } \\
0.0\end{array}$ & $\begin{array}{l}0.1 \text { to } \\
9.0\end{array}$ & 9.1 to 26.0 & $\begin{array}{l}26.1 \text { to } \\
32.0\end{array}$ & $\begin{array}{l}32.1 \text { to } \\
38.0\end{array}$ & $\begin{array}{l}38.1 \text { to } \\
46.0\end{array}$ & $>46.0$ & \\
\hline $\begin{array}{l}\text { Class of thermal } \\
\text { stress }\end{array}$ & -5 & -4 & -3 & -2 & -1 & 0 & +1 & +2 & +3 & +4 & - \\
\hline January & & 0.32 & 3.64 & 7.00 & 0.07 & & & & & & 11.03 \\
\hline February & & & 1.49 & 8.57 & 1.06 & & & & & & 11.11 \\
\hline March & & 0.00 & 1.57 & 7.04 & 4.09 & 0.01 & & & & & 12.71 \\
\hline April & & & 0.23 & 2.98 & 3.46 & 1.73 & & & & & 8.41 \\
\hline May & & & 0.23 & 2.98 & 3.46 & 1.73 & & & & & 5.76 \\
\hline June & & & & & 0.00 & 4.82 & 1.02 & 0.07 & & & 5.91 \\
\hline July & & & & & 0.00 & 2.22 & 2.02 & 0.31 & 0.00 & & 4.56 \\
\hline August & & & & & & 2.07 & 0.61 & 0.35 & 0.03 & & 3.06 \\
\hline September & & & & 0.34 & 3.05 & 4.34 & & & & & 7.74 \\
\hline October & & & & 2.48 & 6.92 & 1.31 & & & & & 10.71 \\
\hline November & & & 0.11 & 5.13 & 3.66 & 0.10 & & & & & 8.99 \\
\hline December & & 0.00 & 1.96 & 7.58 & 0.47 & & & & & & 10.00 \\
\hline Total (\%) & - & 0.32 & 9.22 & 44.10 & 26.25 & 18.35 & 3.65 & 0.73 & 0.03 & - & 100 \\
\hline
\end{tabular}

original scores that aim at the best representation of the response variable, hereafter the number of RTI admissions $(Y)$. It is a useful technique when the problem of multi-colinearity appears (e.g., between the UTCI and temperature). As part of PLS-R analyses, the procedure of importance for the projection (VIP) for each explanatory variable, hereafter meteorological factor $(X)$ was performed to show which of them contribute most to the model. A VIP value $>1$ indicates that the variable is very relevant in the process of explaining $Y$, whereby parameters with a VIP $<0.8$ contribute little to the prediction (Henningsson et al. 2001). All PLS-R analyses were performed using the XLSTAT ver. 2018.3 software for data analysis and statistical application available for Microsoft Excel® by Addinsoft.

\section{Mathematical analysis}

For reasons explained in the Introduction and referring to the aim of the study (the Monday effect, lack of event continuity), in order to calculate the relationship between the UTCI and the number of admissions for RTI, a mathematical method of curve fitting was applied.

By an infectious disease outbreak we mean the rapid increase in the number of admissions to healthcare system institutions. To identify the outbreak, we adopted the following real-valued functions (Eq. 2and Eq. 3):

$f_{1}(t):=e^{\frac{w_{t}-w_{t-1}}{w_{t-1}}}-1$ and

$f_{2}(t):=e^{\frac{w_{t}-w_{t-2}}{w_{t-2}}}-1$,

where $w_{t}$ denotes the number of admissions during the week number $t, w_{t-1}$ denotes the number of admissions during the week number $t-1$, and $w_{t-2}$ denotes the number of admissions during the week number $t-2$. Notice that $f_{1}\left(f_{2}\right.$, respectively) measures the exponential of the relative increase in the number of admissions with respect to the number of admissions the week before ( 2 weeks before, respectively). Therefore $f_{1}$ and $f_{2}$ grow exponentially with the relative increase of admissions.

To determine a relationship between admissions and UTCI values, we take the extremal (minimum or maximum) value of daily UTCI from each week (i.e., for each week we set a UTCI value as the extremal UTCI value among the corresponding seven daily ones). Note that UTCI values associated to colder thermal stress occur in the winter season, and those associated to hotter thermal stress occur in summer season. Thus, the UTCI value can be approximated by a periodic function of time (within a 1-year period). We use the following function (Eq.4):

$g(t)=a_{0}+a_{1} \cos (A t)+b_{1} \sin (A t)$

and calculate the coefficients $a_{0}, a_{1}, b_{1}$, and A using Curve Fitting Tool from Matlab (The MathWorks). The goodness of the curve fitting is expressed using the $R$-squared [Eq. 5 - Eq. 8] 


$$
\begin{aligned}
& R \text {-squared }=1-\frac{S}{T}, \\
& S=\sum_{i=1}^{n}\left(y\left(t_{i}\right)-g\left(t_{i}\right)\right)^{2}, \\
& T=\sum_{i=1}^{n}\left(y\left(t_{i}\right)-\bar{y}\right)^{2}, \\
& \bar{y}=\frac{1}{n} \sum_{i=1}^{n} y\left(t_{i}\right),
\end{aligned}
$$

where $t_{i}$ denotes the $i$ th week, $y\left(t_{i}\right)$ is the UTCI value in the $i$ th week, and $g\left(t_{i}\right)$ is the predicted UTCI value in the $i$ th week. Next, we find values of the function, i.e., the UTCI values, corresponding to the weeks in which the outbreaks occurred.

\section{Ethic statement}

This is a retrospective epidemiological study of medical events registered routinely in the healthcare system. Such observational analyses do not require the consent of the Ethical Committee. Data necessary for analysis were obtained with consent of the heads of all four medical institutions (data were anonymous) and provided by them. Personal details of patients were not processed during the study.

\section{Results}

The analysis of daily medical consultations of patients with RTI revealed an evident seasonal pattern during a 4-year observation period (Fig. 2). The curve illustrating admissions for RTI is of sinusoidal shape which adversely follows the sinusoidal waveform of UTCI values. Extremely high UTCI values, generally achieved in summer, correspond to minimal numbers of patients' consultations for RTI, and this tendency is seen as reversed in winter: low UTCI values correspond to increased numbers of admissions for RTI.

The inversely proportional relationship of daily changes in the number of patients with RTI in relation to UTCI values is confirmed when comparing the share of infectious diseases in the groups of females and males in relation to UTCI classes (Fig. 3). Irrespective of gender, a statistically significantly higher number of consultations for RTI was revealed for UTCI classes $-3,-2$, and -1 (one-way ANOVA, Tukey's test, $p<0.001$ ), whereas UTCI classes $+1,+2$, and +3 created a homogenous group with a statistically significantly lower number of admissions of patients with RTI (Fig. 3). UTCI 0 represents a thermoneutral class that differs significantly from other UTCI classes (except for class -1 for males).

Using daily numbers of admissions for RTI in relation to UTCI values yields satisfactory results in analyzing longterm relationships (e.g., seasonal patterns), demonstrating a generalized cause-effect trend (Fig. 2). Short-term data analyses, however, require careful attention due to the already mentioned "Monday effect", as a result of which after weekends and holidays, when primary care centers are closed, aggregated numbers of admissions were observed (Table 4).

Having a complementary epidemiological and meteorological dataset of many years at our disposal, we used a mathematical model based on the curve fitting model (Fig. 4) to calculate an actual time lag of epidemiological outbreaks. In order to reduce "the Monday effect", we used temporal (weekly) time intervals $(N=208)$. We obtained four distinct outbreaks (see Fig. 4) in the dataset: I (between 36 and 38 weeks of observation) (Autumn 2012); II (between 88 and 90 weeks of observation) (Autumn 2013); III (between 140 and 142 weeks of observation) (Autumn 2014), and IV (between 192 and 194 weeks of observation) (Autumn 2015). In the case

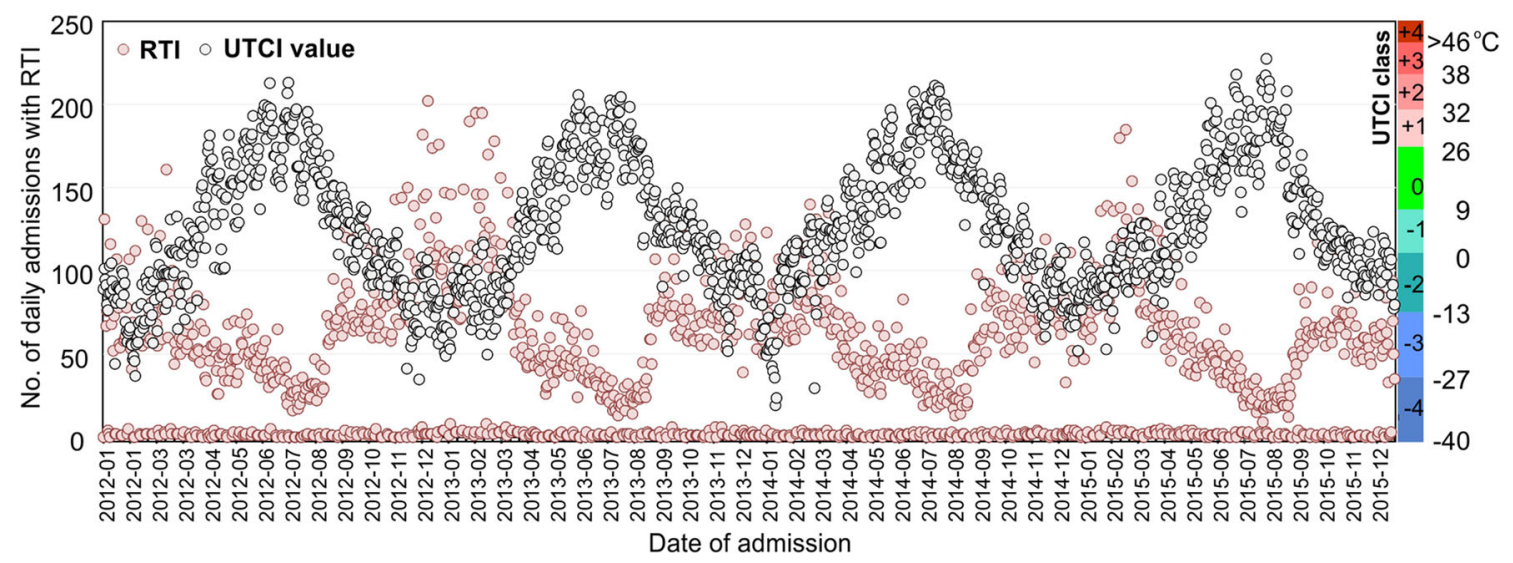

Fig. 2 Actual daily number of consultations for RTI within the healthcare system in the city of Olsztyn and UTCI values in the analyzed period of 20122015 


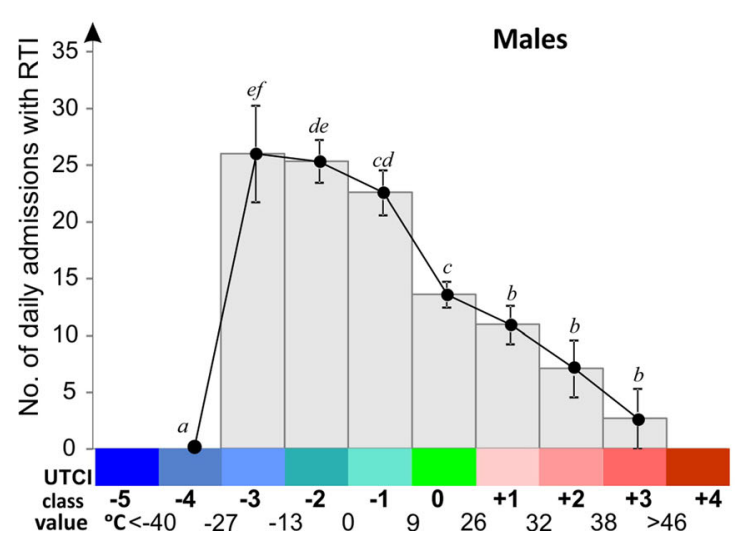

Fig. 3 Histograms of males and females admissions for RTI according to UTCI class. Analysis of variance (one-way ANOVA) was used to test differences between groups of males and females with RTI according to

of each outbreak (I-IV, Fig. 4), the number of weekly admissions was more than doubled within 2 weeks.

The application of the infection prediction model based on the weekly data is presented as a graph of the function $g(t)$ in Fig. 5.

With the use of a Matlab Curve Fitting Tool, the coefficients applied to Eq. 3 are as follows: $a_{0}=-1.23 ; a_{1}=-$ $15.57 ; b_{1}=-7.16 ; \mathrm{A}=0.12$, whereas the goodness of the curve fitting (Eqs. $4-6$ ) expressed by $R-$ squared $=0.82$. We obtained the following values of $g$ corresponding to weeks in which the four outbreaks (see Fig. 4) occurred:

$$
\begin{aligned}
g I(w 37) & =9.85 ; g I I(w 89)=10.41 ; g I I I(w 141) \\
& =10.94 ; g I V(w 193)=11.45
\end{aligned}
$$

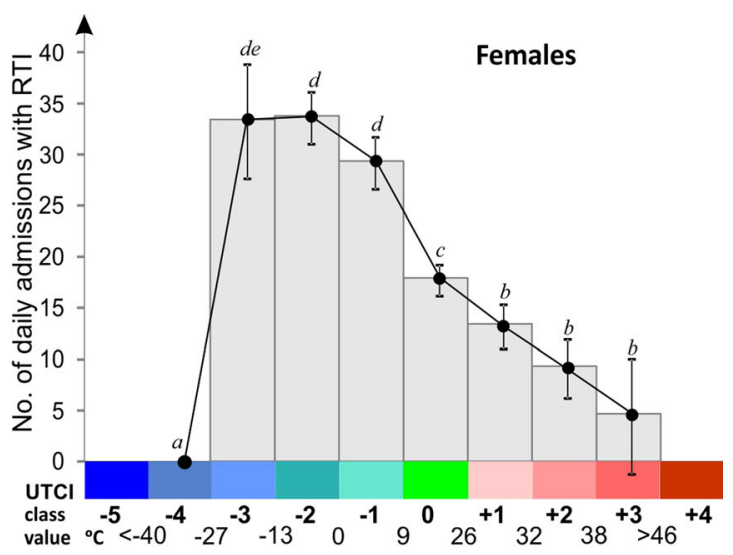

the UTCI class. The groups with the same letter are not statistically different in Tukey's test at $p<0.001$

This means that the values of the function $g(t)$, i.e., the UTCI values, at the observed outbreaks ranged from 9.85 to $11.45^{\circ} \mathrm{C}$ (Fig. 5). Thus, in weeks corresponding to the outbreaks, the function decreases and attains an average value of about 10.5. Moreover, in order to eliminate the impact of "the Monday effect" and confirm a general relationship between UTCI and RTI, we performed linear correlation analysis (Fig. 6) based on weekly data. It demonstrates a strong inverse correlation $(r=-0.757)$ between UTCI values (weekly mean) and the number of admissions for RTI.

To visualize the multidimensional data structure between UTCI values, meteorological parameters investigated, and the number of admissions among females and males, a biplot of scores and correlation loadings were constructed based on a

Table 4 Matrix of Pearson's correlation coefficients between the number of admissions on a given day and on consecutive days following a particular

\begin{tabular}{|c|c|c|c|c|c|c|c|c|c|c|c|c|c|c|c|}
\hline & $\mathrm{D}+0$ & $\mathrm{D}+1$ & $\mathrm{D}+2$ & $\mathrm{D}+3$ & $\mathrm{D}+4$ & $\mathrm{D}+5$ & $\mathrm{D}+6$ & $\mathrm{D}+7$ & $\mathrm{D}+8$ & $\mathrm{D}+9$ & $\mathrm{D}+10$ & $\mathrm{D}+11$ & $\mathrm{D}+12$ & $\mathrm{D}+13$ & $D+14$ \\
\hline $\mathrm{D}+0$ & - & & & & & & & & & & & & & & \\
\hline $\mathrm{D}+1$ & $* *$ & - & & & & & & & & & & & & & \\
\hline $\mathrm{D}+2$ & $*$ & $* *$ & - & & & & & & & & & & & & \\
\hline $\mathrm{D}+3$ & $*$ & $*$ & $* *$ & - & & & & & & & & & & & \\
\hline $\mathrm{D}+4$ & $*$ & $*$ & $*$ & $* *$ & - & & & & & & & & & & \\
\hline $\mathrm{D}+5$ & $*$ & $*$ & $*$ & $*$ & $* *$ & - & & & & & & & & & \\
\hline$D+6$ & $* *$ & $*$ & $*$ & $*$ & $*$ & $* *$ & - & & & & & & & & \\
\hline $\mathrm{D}+7$ & $* * *$ & $* *$ & $*$ & $*$ & $*$ & $*$ & $* *$ & - & & & & & & & \\
\hline $\mathrm{D}+8$ & $* *$ & $* * *$ & $* *$ & $*$ & $*$ & $*$ & $*$ & $* *$ & - & & & & & & \\
\hline $\mathrm{D}+9$ & $*$ & $* *$ & $* * *$ & $* *$ & $*$ & $*$ & $*$ & $*$ & $* *$ & - & & & & & \\
\hline $\mathrm{D}+10$ & $*$ & $*$ & $* *$ & $* * *$ & $* *$ & $*$ & $*$ & * & $*$ & $* *$ & - & & & & \\
\hline $\mathrm{D}+11$ & $*$ & $*$ & $*$ & $* *$ & $* * *$ & $* *$ & $*$ & $*$ & $*$ & $*$ & $* *$ & - & & & \\
\hline $\mathrm{D}+12$ & $*$ & $*$ & $*$ & $*$ & $* *$ & $* * *$ & $* *$ & $*$ & $*$ & $*$ & $*$ & $* *$ & - & & \\
\hline $\mathrm{D}+13$ & $* *$ & * & $*$ & $*$ & $*$ & $* *$ & $* * *$ & $* *$ & $*$ & $*$ & $*$ & $*$ & $* *$ & - & \\
\hline $\mathrm{D}+14$ & $* * *$ & $* *$ & $*$ & $*$ & $*$ & $*$ & $* *$ & $* * *$ & $* *$ & $*$ & $*$ & $*$ & $*$ & $* *$ & - \\
\hline
\end{tabular}
UTCI value

$\mathrm{D}+0$ denotes a number of admissions observed for the UTCI 0 value on the same day; $\mathrm{D}+1$ refers to the number of admissions with a 1 -day lag, $\mathrm{D}+2$ two-day lag, etc. ${ }^{*} r$ ranged from 0.085 to $0.138 ;{ }^{*} r$ ranged from 0.229 to $0.265 ;{ }^{*} * *$ ranged from 0.841 to 0.876 at $p<0.001$ 
Fig. 4 Graph f_1 (solid red line) showing a relative increase in weekly admissions for RTI in Olsztyn in the period of 20122015 when compared with a 1 week lag and graph f_2 (dashed black line) showing a relative increase in weekly admissions for RTI when compared with a 2week lag. I, II, III, and IVoutbreaks of admissions with RTI observed in the period 2012-2015

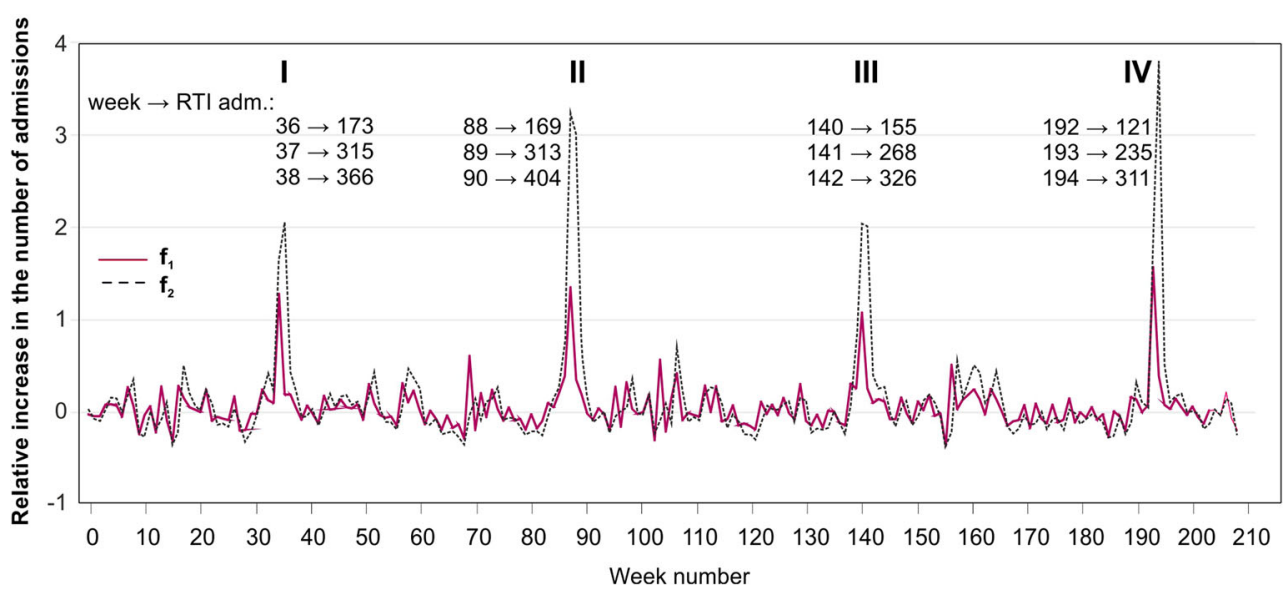

PLS-R model (Fig. 7A). The plot graphically summarizes which of the weather-related factors controls RTI. In component $1,49.4 \%$ of the variance in the set of explanatory variables $(X)$ was used to explain $54.7 \%$ of the variance for the response variables $(Y)$. In component $2,64.8 \%$ in the set of explanatory variables $X$ was used to explain $57.7 \%$ of the response variables $(Y)$. Q2, as a measure of goodness of prediction, showed that component 1 and component 2 almost equally contribute to the model quality Q2 (52.8\% and 52.3\%, respectively).

Among meteorological factors controlling the largest number of admissions for RTI, the UTCI and air temperature values were highly negatively correlated $(r=-0.998$, $p<0.001$ ), regardless of gender (Fig. 7A). RTI admissions were generally less associated with RH $(r=0.521 p<0.01)$, whereas atmospheric pressure $\left(\mathrm{P}_{\mathrm{atm}}\right)$ and wind speed (WS) appeared not to be statistically significant factors as $p>0.05$. Important explanatory variables (VIP $>1$ ) in the weatherfactored projection for RTI (Fig. 7C) created the following decreasing order: $\mathrm{UTCI}>\mathrm{T}_{\mathrm{air}}>\mathrm{RH}>\mathrm{P}_{\mathrm{atm}}>\mathrm{WS}$.

\section{Discussion}

Respiratory tract infectious diseases are responsible for the majority of admissions to healthcare system institutions
(Fleming et al. 2002). In our study based in Olsztyn, Poland (period 2012-2015), they account for approx. 15\% of the total number of consultations. Such infections are also the major cause of admissions of children and youth (Fig. 1, Table 1) and demonstrate a seasonal pattern (Fig. 2). The number of RTI occurrences depends on air temperature, air humidity, but mostly on UTCI values (Fig. 6). A statistically significant increase in the number of RTI appears when the UTCI class changes, especially when the index value drops by two classes in connection with the appearance of cold stress (Fig. 3).

The presented results of analysis "performed with the curve fitting method based on weekly data" indicate an evident temporal relationship between a change in the thermal climate conditions and the initiation of the epidemiological cascade (Fig. 4), which can be of significance for precautionary planning. Each evident drop in the UTCI value (usually in the autumn season) results within 2 weeks in a significant increase in the number of RTI cases. The UTCI values of the function $g(t)$ for all 4 observed RTI outbreaks ranged from 9.85 to 11.45 UTCI (Fig. 5). However, a further drop in ${ }^{\circ} \mathrm{C}$ values does not lead to such a significant increase in RTI occurrences (Fig. 4). This observation is quite obvious from an epidemiological perspective. RTI, irrespective of etiology, are infectious diseases which are subject to the laws of epidemiological dynamics (Li et al. 2009; Stilianakis and Drossinos 2010).

Fig. 5 Periodic function $g(t)$ of UTCI values $(y)$

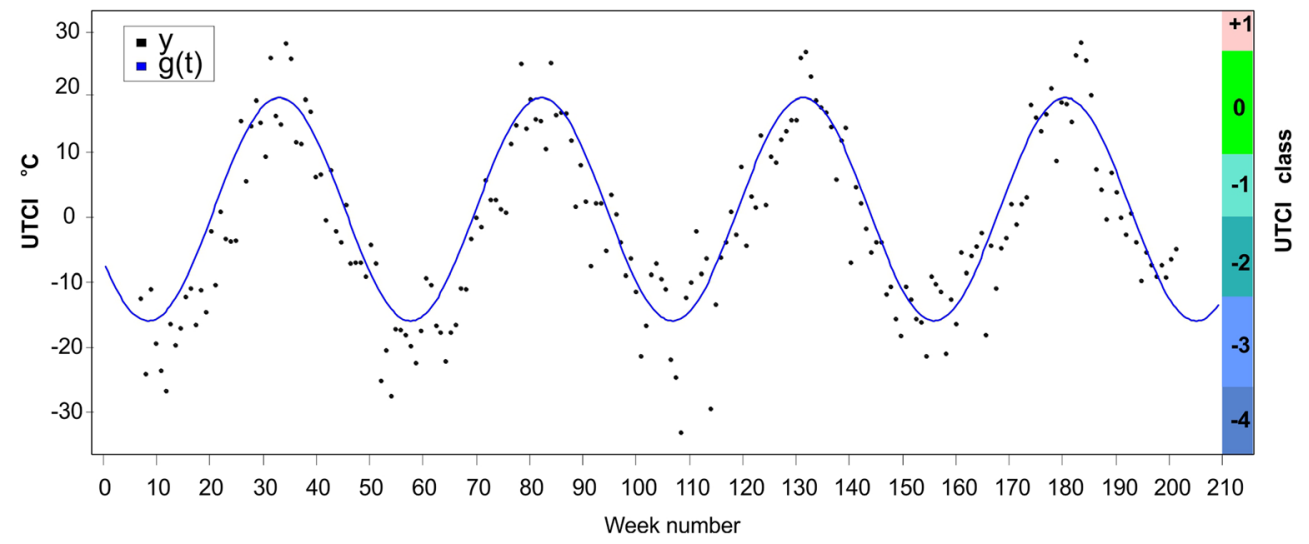




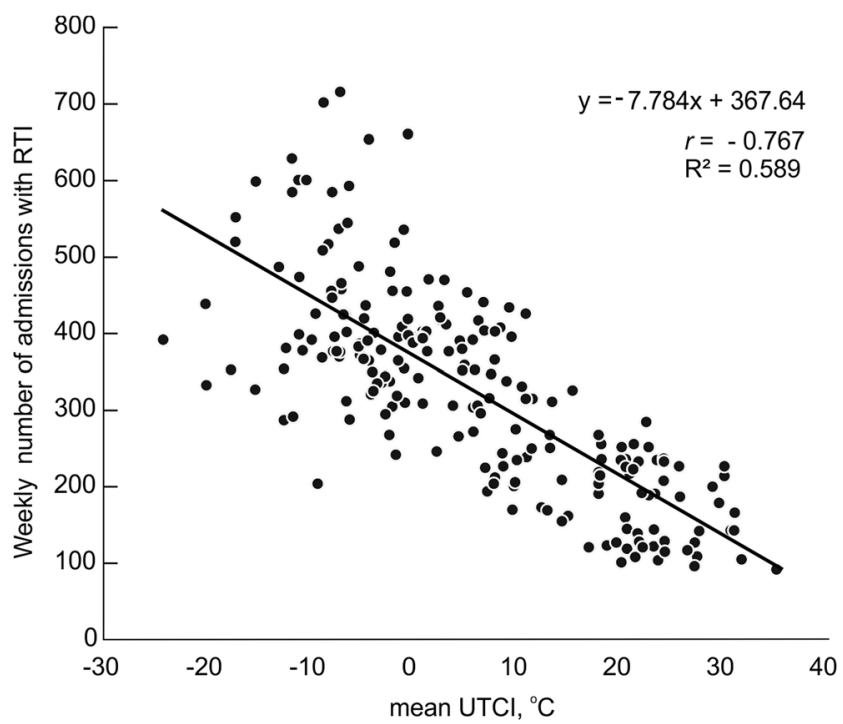

Fig. 6 Linear regression between the weekly number of patients with RTI and corresponding mean UTCI values

This is important because it draws attention to the fact that the relationship between decreased air temperature and increased numbers of RTI cases is not linear. It is very easy, then, to make some simplifications, an example of which is the assumption of continuity of function in relation between atmospheric conditions and the number of diseases due to RTI. If that was the amount, RTI would grow all the time with the decrease of UTCI.

When analyzing the lagged impact of meteorological parameter changes on the epidemiological effect, the analysis of
Pearson's linear correlation coefficients between mean daily values of UTCI and the number of daily consultations for RTI (Table 4) clearly demonstrates a 7-day lag (D+7 and D + 14) in the increased number of admissions in relation to the occurrence of the potential reason, i.e., a drop in the UTCI value or class.

Despite a statistically significant relationship between a decrease in the UTCI value and an increase in the number of admissions for RTI calculated on the basis of a daily dataset, such an analysis, in our opinion, should not be employed for determining the temporal lag and the associated epidemiological forecasting. The relationship termed by us "the Monday effect" (Table 2) burdens such an analysis with a methodological error resulting from the work organization in the healthcare system. A significantly higher number of admissions on Mondays (27.5\%) are associated with the lack of or difficult access to the healthcare system institutions on weekends. We believe that studies based on data obtained from primary care centers should definitely account for the Monday effect (Tables 2 and 4). Thus, we recommend longer intervals to be used in such analyses. Even if in a given country, primary care centers work within the $24 / 7$ system, accessibility to healthcare institutions on weekends, and holidays is always somewhat limited (duty system, higher fees for service, etc.) (Masseria et al. 2009). In a study based on data collected in Athens (Greece), Nastos and Matzarakis observed a seasonal drop in GP consultations for RTI in December and stresses that this decrease may result from limited accessibility to medical services during Christmas. However, they did not a

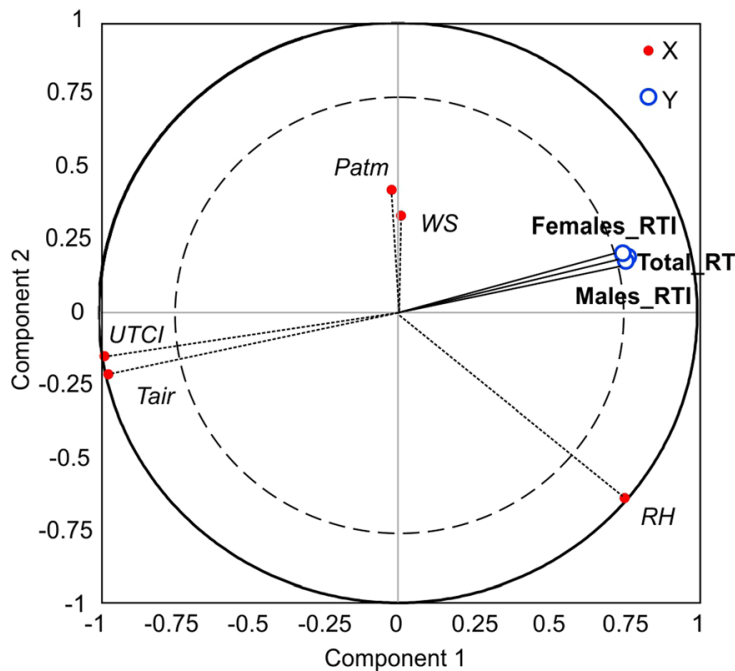

b Model quality

$\begin{array}{llc}\text { Statistics } & \text { Comp. 1 } & \text { Comp. 2 } \\ \text { Q2 } & 0.528 & 0.523 \\ \text { R2Y } & 0.547 & 0.577 \\ \text { R2X } & 0.494 & 0.648\end{array}$

\section{C} VIPs ( 1 Comp / 95\% conf. interval)

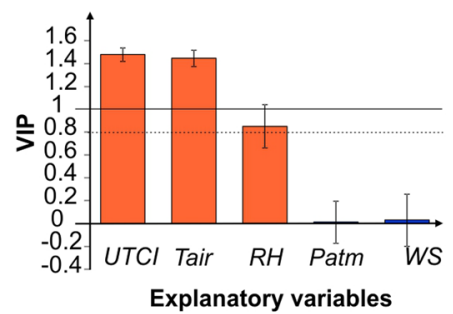

Fig. 7 Correlation circle of partial least squares (PLS) regression (A), illustrating the correlations of infectious diseases (response variables $Y$ ) and meteorological parameters (explanatory variables $X$ ) with the first two axes associated to the first two components. The percentages of the variances in $X$ and $Y$ explained by each variable are indicated on the respective axes. The inner dashed circle denotes the correlation coefficient $r=0.75$. (B) Model quality is based on three quality indices reported: $Q^{2}$ (cum), $R^{2} Y$ (cum), and $R^{2} X(\mathrm{cum})$. The $Q^{2}$ (cum) index represents a global contribution of the components and identifies the most stable model when it approaches 1. (C) VIPs (variable importance for the projection) for each explanatory variable. Explanatory variables that contribute most to the PLS model are characterized by VIPs $>1$ and are indicated in red 
analyze accessibility to medical services on weekends (Nastos and Matzarakis 2006). Some authors circumvented this problem by providing weekly analyses (Costilla-Esquivel et al. 2014; Falagas et al. 2008; Sundell et al. 2016). Such a mode of analysis, despite retaining basic relationships (Fig. 6), precludes the possibility of calculating the lag in the epidemiological effect in relation to the actual meteorological situation.

As a result of our research, we also recognized that the human thermal environment leading to RTI occurrences cannot be represented with just a single parameter such as air temperature due to its various degrees of impacting on the human organism in different climatic zones. According to Jendritzky, for warm conditions, such indices consist usually of combinations of air temperature and one of a variety of indices for humidity, while for cold conditions the combination consists typically of air temperature related in some way with wind speed (Jendritzky et al. 2012). A number of papers have been published that demonstrate relationships between, for instance, humidity and RTI occurrences (Costilla-Esquivel et al. 2014; Gardinassi et al. 2012; Ho et al. 2018; Khor et al. 2012; Makinen et al. 2009). The relationship between air temperature and the number of consultations for RTI in moderate and cold climates is usually the same (the lower the air temperature, the larger the number of admissions for RTI) (Shiue et al. 2014; Donaldson et al. 2012). This correlation, however, may be different in tropical climates or others. While not negating the relationships reported by other authors (in our study air temperature is also significant), we wish to draw attention to the fact that comparisons of results obtained in countries from different climatic zones may lead to erroneous conclusions.

In our opinion, by combining 4 basic meteorological parameters, the UTCI is a definitely more reliable index to be used in analyses of weather-related infections than single or double meteorological parameters (Zare et al. 2018). The analysis of admissions for RTI in the moderate transitional climate of Central and Eastern Europe presented in our study demonstrated a strong impact of both air temperature and relative humidity, and a very weak impact of atmospheric pressure and wind speed (Fig. 7A-C).

The results of our epidemiological study, based on a causeeffect related approach, showed that the UTCI is a promising parameter which could be effectively used in precautionary planning and should be considered in developing appropriate operational products for the public health system. The advantage of the UTCI is its standardized value which might be successfully applied in different climates.

\section{Conclusions}

The UTCI is a valuable predictive parameter for forecasting seasonal increases in RTI occurrences. A statistically significant increase in the number of RTI cases appeared when UTCI values decreased, especially when the UTCI reached strong and very strong cold stress classes. This effect is strongest about 7-14 days following the change in the thermal climate conditions and is not continuous. The described "Monday effect" may blur typical statistical analyses, leading to erroneous conclusions.

\section{Limitations}

Although this study is based on a rather large dataset, the data are collected only from one city and cover a relatively short period of time, given this type of research. Data concerning the number of daily consultations may be periodically smaller than the demand for them. The healthcare system capacity is limited, and it can sometimes be even smaller during RTI epidemics (employees' sickness). This is another argument demonstrating that such analyses should be based on weekly data.

\section{Compliance with ethical standards}

Conflict of interest The authors declare that they have no conflict of interest.

Open Access This article is distributed under the terms of the Creative Commons Attribution 4.0 International License (http:// creativecommons.org/licenses/by/4.0/), which permits unrestricted use, distribution, and reproduction in any medium, provided you give appropriate credit to the original author(s) and the source, provide a link to the Creative Commons license, and indicate if changes were made.

\section{References}

Blazejczyk K (1994) New climatological-and-physiological model of the human heat balance outdoor (MENEX) and its applications in bioclimatological studies in different scales. Zeszyty IgiPZ PAN 28:27-58

Błażejczyk K (2011) Mapping of UTCI in local scale (the case of Warsaw). Prace i Studia Geograficzne WGSR UW 47:275-283

Błażejczyk K, McGregor G (2008) Mortality in European cities and its relations to biothermal conditions. Klimat i bioklimat miast. Wydawnictwo Uniwersytetu łódzkiego, pp 13-324

Blazejczyk K, Epstein Y, Jendritzky G, Staiger H, Tinz B (2012) Comparison of UTCI to selected thermal indices. Int J Biometeorol 56(3):515-535. https://doi.org/10.1007/s00484-011-0453-2

Bröde P (2000) UTCI universal thermal climate index. Leibniz Research Centre for Working Environment and Human Factors. http://www. utci.org/index.php. Accessed 25 Apr 2019

Brode P, Fiala D, Blazejczyk K, Holmer I, Jendritzky G, Kampmann B, Tinz B, Havenith G (2012) Deriving the operational procedure for the universal thermal climate index (UTCI). Int J Biometeorol 56(3): 481-494. https://doi.org/10.1007/s00484-011-0454-1

Buckingham-Jeffery E, Morbey R, House T, Elliot AJ, Harcourt S, Smith GE (2017) Correcting for day of the week and public holiday effects: improving a national daily syndromic surveillance service for detecting public health threats. BMC Public Health 17(1):477

Costilla-Esquivel A, Corona-Villavicencio F, Velasco-Castañón J, Medina-De La Garza C, Martinez-Villarreal R, Cortes-Hernández D, Ramirez-Lopez L, Gonzalez-Farias G (2014) A relationship 
between acute respiratory illnesses and weather. Epidemiol Infect 142(7):1375-1383

Court A (1948) Wind chill. Bull Am Meteorol Soc 29:487-493

Danielides V, Nousia CS, Patrikakos G, Bartzokas A, Lolis CJ, Milionis HJ, Skevas A (2002) Effect of meteorological parameters on acute laryngitis in adults. Acta Otolaryngol 122(6):655-660

Donaldson GC, Goldring JJ, Wedzicha JA (2012) Influence of season on exacerbation characteristics in patients with COPD. Chest 141(1): 94-100

du Prel J-B, Puppe W, Gröndahl B, Knuf M, Weigl F, Schaaff F, Schaaff F, Schmitt H-J (2009) Are meteorological parameters associated with acute respiratory tract infections? Clin Infect Dis 49(6):861-868

Epstein Y, Moran DS (2006) Thermal comfort and the heat stress indices. Ind Health 44(3):388-398

Falagas ME, Theocharis G, Spanos A, Vlara LA, Issaris EA, Panos G, Peppas G (2008) Effect of meteorological variables on the incidence of respiratory tract infections. Respir Med 102(5):733-737. https:// doi.org/10.1016/j.rmed.2007.12.010

Fiala D, Lomas KJ, Stohrer M (1999) A computer model of human thermoregulation for a wide range of environmental conditions: the passive system. J Appl Physiol (1985) 87(5):1957-1972. https://doi.org/10.1152/jappl.1999.87.5.1957

Fiala D, Lomas KJ, Stohrer M (2001) Computer prediction of human thermoregulatory and temperature responses to a wide range of environmental conditions. Int J Biometeorol 45(3):143-159

Fiala D, Havenith G, Brode P, Kampmann B, Jendritzky G (2012) UTCIFiala multi-node model of human heat transfer and temperature regulation. Int J Biometeorol 56(3):429-441. https://doi.org/10. 1007/s00484-011-0424-7

Fielder CP (1989) Effect of weather conditions on acute laryngotracheitis. J Laryngol Otol 103(2):187-190

Fleming D, Smith G, Charlton J, Charlton J, Nicoll A (2002) Impact of infections on primary care-greater than expected. Commun Dis Public Health 5(1):7-12

Gardinassi LG, Marques Simas PV, Salomao JB, Durigon EL, Zanetta Trevisan DM, Cordeiro JA, Lacerda MN, Rahal P, de Souz FP (2012) Seasonality of viral respiratory infections in southeast of Brazil: the influence of temperature and air humidity. Braz J Microbiol 43(1):98 108. https://doi.org/10.1590/S1517-838220120001000011

Hajat S, Bird W, Haines A (2004) Cold weather and GP consultations for respiratory conditions by elderly people in 16 locations in the UK. Eur J Epidemiol 19(10):959-968

Henningsson M, Sundbom E, Armelius BA, Erdberg P (2001) PLS model building: a multivariate approach to personality test data. Scand J Psychol 42(5):399-409

Ho NT, Thompson C, Nhan LNT, Van HMT, Dung NT, Tran My P, Quang VM, Minh NNQ, Tuan TA, Hung NT, Tuan HM, Vinh Chau NV, Wolbers M, Thwaites GE, Choisy M, Baker S (2018) Retrospective analysis assessing the spatial and temporal distribution of paediatric acute respiratory tract infections in Ho Chi Minh City, Vietnam. BMJ Open 8(1):e016349. https://doi.org/10.1136/ bmjopen-2017-016349

Jendritzky G, Havenith G, Weihs P, Batchvarova E (2009) Towards a universal thermal climate index UTCI for assessing the thermal environment of the human being. Final Report COST Action 730:1-26

Jendritzky G, de Dear R, Havenith G (2012) UTCI — why another thermal index? Int J Biometeorol 56(3):421-428

Khor CS, Sam IC, Hooi PS, Quek KF, Chan YF (2012) Epidemiology and seasonality of respiratory viral infections in hospitalized children in Kuala Lumpur, Malaysia: a retrospective study of 27 years. BMC Pediatr 12:32. https://doi.org/10.1186/1471-2431-12-32

Laschewski G, Jendritzky G (2002) Effects of the thermal environment on human health: an investigation of 30 years of daily mortality data from SW Germany. Clim Res 21(1):91-103
Li P, Chan S (2000) Application of a weather stress index for alerting the public to stressful weather in Hong Kong. Meteorol Appl 7(4):369-375

Li S, Eisenberg JN, Spicknall IH, Koopman JS (2009) Dynamics and control of infections transmitted from person to person through the environment. Am J Epidemiol 170(2):257-265

Liu Y, Liu J, Chen F, Shamsi BH, Wang Q, Jiao F, Qiao Y, Shi Y (2016) Impact of meteorological factors on lower respiratory tract infections in children. J Int Med Res 44(1):30-41. https://doi.org/10. $1177 / 0300060515586007$

Lowe R, Gasparrini A, Van Meerbeeck CJ, Lippi CA, Mahon R, Trotman AR, Rollock L, Hinds AQJ, Ryan SJ, Stewart-Ibarra AM (2018) Nonlinear and delayed impacts of climate on dengue risk in Barbados: a modelling study. PLoS Med 15(7):e1002613. https:// doi.org/10.1371/journal.pmed.1002613

Makinen TM, Juvonen R, Jokelainen J, Harju TH, Peitso A, Bloigu A, Silvennoinen-Kassinen S, Leinonen M, Hassi J (2009) Cold temperature and low humidity are associated with increased occurrence of respiratory tract infections. Respir Med 103(3):456-462. https://doi. org/10.1016/j.rmed.2008.09.011

Masseria C, Irwin R, Thomson S, Gemmill M, Mossialos E (2009) Primary Care in Europe: policy brief. London: LSE

Masterton J, Fa R (1979) A method of quantifying human discomfort due to excessive heat and humidity. cli 1-79: aes, environment Canada. Downsview, Ontario

Matzarakis A, Mayer H (1996) Another kind of environmental stress: thermal stress. WHO Newslett 18(1996):7-10

McGregor GR (2012) Special issue: universal thermal comfort index (UTCI). Int J Biometeorol 56(3):419-419

Nastos PT, Matzarakis A (2006) Weather impacts on respiratory infections in Athens, Greece. Int J Biometeorol 50(6):358-369. https:// doi.org/10.1007/s00484-006-0031-1

NICE CfCPa (2008) Respiratory tract infections-antibiotic prescribing: prescribing of antibiotics for self-limiting respiratory tract infections in adults and children in primary care

Osczevski R, Bluestein M (2005) The new wind chill equivalent temperature chart. Bull Am Meteorol Soc 86(10):1453-1458

Pantavou K, Lykoudis S, Nikolopoulou M, Tsiros IX (2018) Thermal sensation and climate: a comparison of UTCI and PET thresholds in different climates. Int J Biometeorol 62(9):1695-1708

Peel MC, Finlayson BL, McMahon TA (2007) Updated world map of the Köppen-Geiger climate classification. Hydrol Earth Syst Sci Discuss 4(2):439-473

Shiue I, Muthers S, Bearman N (2014) The role of cold stress in predicting extra cardiovascular and respiratory admissions. Int $\mathrm{J}$ Cardiol 172(1):e109-e110

Stilianakis NI, Drossinos Y (2010) Dynamics of infectious disease transmission by inhalable respiratory droplets. J R Soc Interface 7(50): 1355-1366. https://doi.org/10.1098/rsif.2010.0026

Sundell N, Andersson L-M, Brittain-Long R, Lindh M, Westin J (2016) A four year seasonal survey of the relationship between outdoor climate and epidemiology of viral respiratory tract infections in a temperate climate. J Clin Virol 84:59-63

The MathWorks I. https://www.mathworks.com/help/curvefit/fit.html. Accessed 06 DEC 2018

WHO (1992) The ICD-10 classification of mental and behavioural disorders: clinical descriptions and diagnostic guidelines. World Health Organization, Geneva

Whynes DK, Falk-Whynes J, Pringle M (1999) Trends in acute admissions: a study of one English district general hospital. J Public Health 21(4):459-463

Zare S, Hasheminejad N, Shirvan HE, Hemmatjo R, Sarebanzadeh $\mathrm{K}$, Ahmadi S (2018) Comparing universal thermal climate index (UTCI) with selected thermal indices/environmental parameters during 12 months of the year. Weather Climate Extremes 19:49-57 